\title{
Nefrectomía radical y escisión de trombo nivel IV con derivación cardiopulmonar, hipotermia profunda y paro circulatorio: reporte de un caso y revisión de la bibliografía
}

Izquierdo-Luna JS, Campos-Salcedo JG, Estrada-Carrasco CE, Torres-Gómez JJ, Hernández-Palacios GA, y colaboradores.

\section{Resumen}

ANTECEDENTES: el carcinoma de células renales se asocia con invasión vascular. El tratamiento de los trombos tumorales nivel IV implica la colaboración de un equipo multidisciplinario. Aún se discuten las estrategias de tratamiento para este tipo de pacientes.

CASO CLÍNICO: paciente masculino de 56 años de edad, que acudió a consulta con cuadro típico de cáncer renal; durante la exploración se detectó un trombo en la aurícula derecha y metástasis pulmonares. Con intervención multidisciplinaria se efectuaron la nefrectomía radical y la resección del trombo, con derivación cardiopulmonar, hipotermia profunda y paro circulatorio. Con la técnica implementada se observó evolución satisfactoria. Se inició tratamiento con inhibidores de tirosina cinasa, con excelente reacción al medicamento y buena calidad de vida a 11 meses de seguimiento.

CONCLUSIONES: se recomienda que los pacientes en estadio IV, con una masa tumoral potencialmente resecable se sometan a nefrectomía citorreductora antes de la terapia sistémica. La función de la terapia blanco en pacientes con histología diferente a la de células claras no está bien definida. Este tipo de tumores debe incluirse en el análisis de ensayos clínicos.

PALABRAS CLAVE: tumor renal metastásico, trombo auricular.
Servicio de Urología, Hospital Central Militar. Escuela Militar de Graduados de Sanidad, Universidad del Ejército y Fuerza Aérea. Ciudad de México, México.

Recibido: diciembre 2016

Aceptado: junio 2017

Correspondencia

Juan Samuel Izquierdo Luna drsamuelizquierdo@gmail.com

Este artículo debe citarse como Izquierdo-Luna JS, Campos-Salcedo JG, EstradaCarrasco CE, y col. Nefrectomía radical y escisión de trombo nivel IV con derivación cardiopulmonar, hipotermia profunda y paro circulatorio: reporte de un caso y revisión de la bibliografía. Rev Mex Urol. 2017 jul-agos;77(4):307-311.

DOI: https://doi.org/10.24245/revmexurol.v77i4.1105 


\section{Radical nephrectomy plus level IV thrombus excision with cardiopulmonary bypass, deep hypothermia, and circulatory arrest: a case report and literature review}

Izquierdo-Luna JS, Campos-Salcedo JG, Estrada-Carrasco CE, Torres-Gómez JJ, Hernández-Palacios GA, et al.

\begin{abstract}
BACKGROUND: Renal cell carcinoma has a unique propensity for vascular invasion. Level IV tumor thrombi require multidisciplinary collaboration. The best strategy for managing such patients is still a subject of debate.

CLINICAL CASE: A 56-year-old man presented with typical symptoms of kidney cancer and during work-up a tumor thrombus in the right atrium and pulmonary metastases were detected. A multidisciplinary team performed radical nephrectomy plus resection of the thrombus through cardiopulmonary bypass, deep hypothermia, and circulatory arrest, with excellent patient progression. Treatment with tyrosinekinase inhibitors was then begun and at the 11th month of follow-up, the patient has good quality of life and his disease is stable.
\end{abstract}

CONCLUSION: Cytoreductive nephrectomy before systemic therapy is recommended in stage IV patients with a potentially resectable tumor. The role of targeted therapy in histologic results other than clear cell disease is not well defined. Enrollment in clinical trials is the preferred strategy for those types of tumor.

KEYWORDS: Metastatic renal tumor; Atrial thrombus
Urology Service, Hospital Central Militar Escuela Militar de Graduados de Sanidad, Universidad del Ejército y Fuerza Aérea. Mexico City, Mexico.

Correspondence

Juan Samuel Izquierdo Luna drsamuelizquierdo@gmail.com

\section{ANTECEDENTES}

El carcinoma de células renales representa 3\% de todas las neoplasias y tiene una característica única: la propensión para invasión vascular. ${ }^{1}$ Se ha reportado la afectación de la vena renal en $33 \%$, de la vena cava en $4-15 \%$ y su extensión a la aurícula derecha en solo $0.7 \%$ de los pacientes. ${ }^{2}$ El tratamiento de los trombos nivel IV implica la colaboración de un cirujano cardiotorácico para remover la totalidad del trombo auricular. Existen diversas técnicas para el tratamiento de estos tumores; sin embargo, debido al limitado número de casos estudiados y al seguimiento, sigue discutiéndose cuál es la mejor técnica quirúrgica en estos pacientes. La hipotermia profunda con paro circulatorio es el método más utilizado, pues ha demostrado las 
mayores ventajas, sin aumentar el riesgo operatorio ni la tasa de complicaciones. ${ }^{3}$

\section{CASO CLÍNICO}

Paciente masculino de 56 años de edad, con diabetes y antecedente de tabaquismo, quien acudió al servicio de Urgencias por pérdida de $10 \mathrm{~kg}$ de peso de dos meses de evolución y hematuria intermitente, concomitante con síntomas de irritación urinaria, que desencadenó un episodio de retención aguda de orina provocada por coágulos. A la exploración física se encontró, como principal hallazgo: masa palpable en el flanco abdominal izquierdo, sin adenomegalias ni signos físicos adicionales de importancia. Los estudios paraclínicos no mostraron disminución de la hemoglobina, pero se observó discreta elevación de la creatinina sérica. La ecografía de la vía urinaria evidenció una masa hipervascular a expensas del riñón izquierdo y coágulos intravesicales. La tomografía contrastada mostró un tumor renal izquierdo, de $13.5 \mathrm{~cm}$ en su diámetro mayor, con trombosis maligna desde la vena renal hasta la aurícula derecha (nivel IV de la clasificación de $\mathrm{Neves}^{4}$ ), nódulos linfáticos retroperitoneales y múltiples sitios de metástasis pulmonares, no susceptibles deresección (Figura 1). Se estadificó como T3cN1M1, etapa clínica IV, y se expuso el caso en junta multidisciplinaria. Se realizaron nefrectomía citorreductora y trombectomía con derivación cardiopulmonar, hipotermia profunda y paro circulatorio mediante abordaje simultáneo abdominal y torácico, durante el cual se dividió el tumor del trombo (Figura 2). Con la técnica implementada el paciente evolucionó favorablemente y egresó al quinto día del posoperatorio. El estudio histopatológico reportó: carcinoma de células renales papilar tipo 2. Se prescribió tratamiento con pazopanib, con base en la tolerancia al mismo. Hasta la fecha, el paciente se encuentra asintomático y estable, a 11 meses de seguimiento.

\section{DISCUSIÓN}

El caso clínico es de un paciente con un cuadro característico de tumor renal (hematuria, masa en flanco, sin dolor), con metástasis al momento del diagnóstico. Durante el establecimiento inicial del diagnóstico se documentaron las metástasis pulmonares y la extensión del trombo hacia la aurícula derecha por tomografía. Una de las características más importantes del carcinoma de células renales es su invasión a la vena renal, que puede desarrollarse como una columna de células que se extiende por la vena cava inferior, incluso hasta las cámaras derechas del corazón. ${ }^{5}$ La extensión de trombos tumorales en la vena cava inferior o la aurícula derecha no ha demostrado influir en la supervivencia de pacientes con carcinoma de células renales; por lo tanto, el tratamiento quirúrgico agresivo sigue siendo el protocolo de primera línea, ${ }^{2}$ además de la prescripción de fármacos sistémicos. Los pacientes con tumores renales con extensión trombótica tienen mayor riesgo de recurrencia que quienes no sufren trombos; del mismo modo, la recurrencia de un tumor renal se asocia con mal pronóstico $y$, por lo tanto, la terapia coadyuvante debe considerarse para la mayoría de los pacientes, aun sin evidencia de metástasis al momento de la nefrectomía. ${ }^{6}$ En relación con la técnica quirúrgica en pacientes con trombos nivel IIIIV, el tratamiento quirúrgico con o sin bypass cardiopulmonar es igualmente efectivo, desde el punto de vista oncológico; sin embargo, aún se discute la embolización preoperatoria de la arterial renal. Asimismo, el abordaje quirúrgico debe individualizarse; la evidencia también sugiere que los pacientes en quienes fue dividido el trombo, como es nuestro caso, comparados con quienes se extrajo en bloque con el riñón, la tasa global de complicaciones no ha sido estadísticamente diferente. ${ }^{7}$ En relación con la evolución perioperatoria, los 


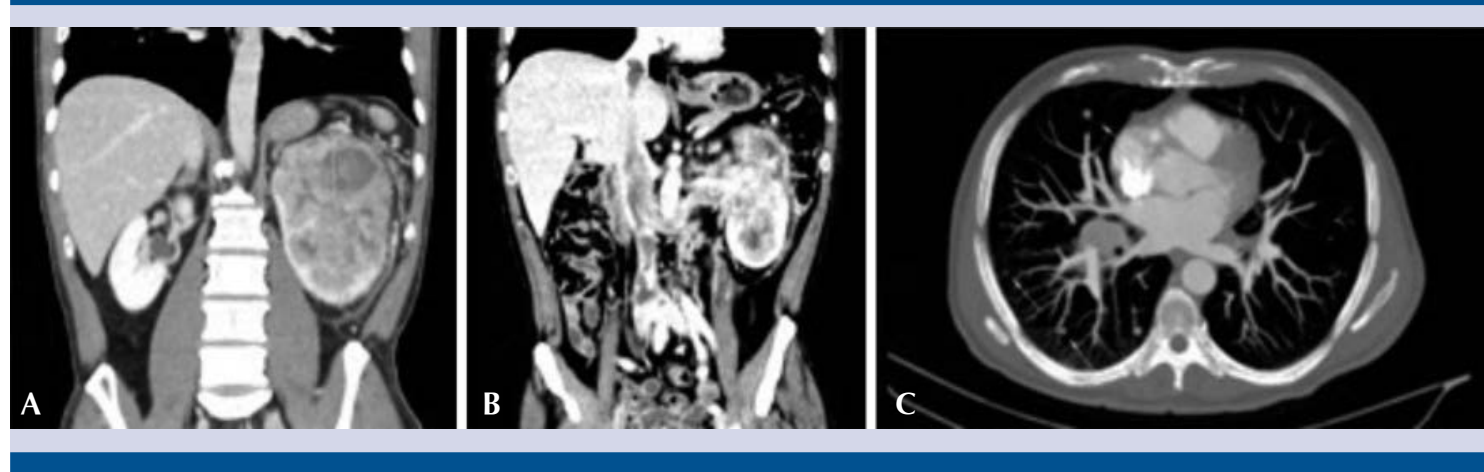

Figura 1. Tomografía contrastada: metástasis pulmonares y trombo en la aurícula derecha (A); trombo tumoral en la vena renal, vena cava inferior y vena cava superior (B); tumor renal izquierdo (C).

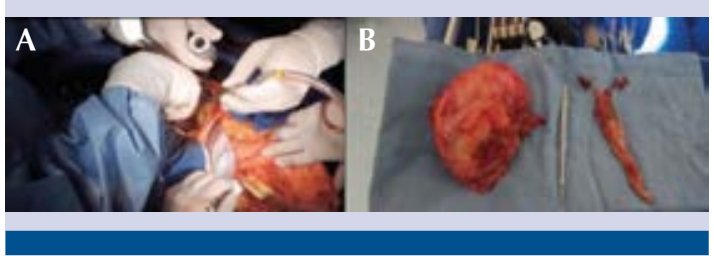

Figura 2. Extracción del trombo desde la aurícula, por la vena cava (A); disección del tumor y trombo (B).

datos disponibles indican que los pacientes con mal estado funcional o hipoalbuminemia tienen mayor riesgo de mortalidad temprana, pero pueden beneficiarse al diferir la cirugía, cuando se optimiza el tratamiento preoperatorio. ${ }^{8}$ En este caso, se trató de un paciente con buen estado funcional, sin complicaciones en el posoperatorio. Un estudio multicéntrico que evaluó la repercusión del subtipo histológico en la supervivencia específica de pacientes con carcinoma de células renales y trombo tumoral, encontró que quienes resultaron con histología papilar, como el caso aquí reportado, tuvieron un pronóstico significativamente peor que quienes mostraron los subtipos de células claras y cromófobo. Un análisis multivariado reportó que la histología papilar se asoció significativamente con la supervivencia específica para carcinoma de células renales, sin tomar en cuenta otros factores clínicos y patológicos conocidos (metástasis ganglionares). ${ }^{9}$ Finalmente, en los pacientes en estadio IV se recomienda nefrectomía citorreductora previa a la terapia sistémica, en quienes tienen una masa tumoral potencialmente resecable. La terapia blanco en sujetos con histología diferente a la de células claras no está bien definida. El reporte de este tipo de tumores debe incluirse en ensayos clínicos; algunos estudios indican que las terapias blanco aprobadas para el carcinoma renal de células claras puede beneficiar a pacientes con otros subtipos histológicos. ${ }^{10}$ Entre los inhibidores de tirosina cinasa, pazopanib y sunitinib muestran eficacia similar, pero los perfiles de seguridad y calidad de vida favorecen al primero. ${ }^{11}$

El tratamiento de pacientes con cáncer renal y trombos metastásicos amerita la participación multidisciplinaria, además de diversos recursos humanos y materiales. Aun en centros de concentración como el nuestro, este tipo de neoplasias son poco frecuentes. El protocolo quirúrgico agresivo y el seguimiento médico son indispensables para la adecuada evolución de los pacientes. 


\section{Financiamiento}

Los autores declaran no haber recibido financiamiento.

\section{Conflicto de intereses}

No existe conflicto de intereses.

\section{REFERENCIAS}

1. Hevia V, Ciancio G, Gómez V. Surgical technique for the treatment of renal cell carcinoma with inferior vena cava tumor thrombus: tips, tricks and oncological results. Springerplus. 2016;5:132.

2. Posacioglu $H$, Ayik M, Zeytunlu M, el al. Management of renal cell carcinoma with intracardiac extension. J Card Surg. 2008;23:754-758.

3. Gaudino M, Lau C, Cammertoni F, et al. Surgical treatment of renal cell carcinoma with cavoatrial involvement: a systematic review of literature. Ann Thorac Surg. 2016;101(3);1213:21.

4. Neves RJ, Zincke H. Surgical treatment of renal cancer with vena cava extension. Br J Urol 1987;59(5):390-395.
5. Lu HT, Chong JL, Othman N, et al. An uncommon and insidious presentation of renal cell carcinoma with tumor extending into the inferior vena cava and right atrium: J Med Case Rep. 2016;10(1):109.

6. Klatte T, Pantuck AJ, Riggs SB, et al. Prognostic factors for renal cell carcinoma with tumor thrombus extension. J Urol. 2007;178:1189-1195.

7. Lardas M, Stewart F, Scrimgeour D, el al. Systematic review of surgical management of nonmetastatic renal cell carcinoma with vena cava thrombus. Eur Urol. 2016;70:265-280.

8. Abel EJ, Thompson RH, Margulis V, et al. Perioperative outcomes following surgical resection of renal cell carcinoma with inferior vena cava thrombus extending above the hepatic veins: a contemporary multicenter experience. Eur Urol. 2014;66:584-592.

9. Tilki D, Nguyen H, Dall'Era MA, et al. Impact of histologic subtype on cancer-specific survival in patients with renal cell carcinoma and tumor thrombus. Eur Urol. 66(3); 577-83. 2013.

10. Motzer RJ, Jonasch E, Agarwal N, et al. Kidney cancer guideline version 1.2015). National Comprehensive Cancer Network, 2015;13(2);151-9.

11. Motzer RJ, Hutson TE, Cella D, et al. Pazopanib versus Sunitinib in metastastic renal-cell carcinoma. N Engl J Med. 2013;369(8):722-731.

\section{AVISO PARA LOS AUTORES}

Revista Mexicana de Urología tiene una nueva plataforma de gestión para envío de artículos: https://www.revisionporpares.com/index.php/RMUrol ahí podrá inscribirse a la base de datos administrada por el sistema Open Journal System (OJS) que ofrece las siguientes ventajas para los autores:

- Subir sus artículos directamente al sistema.

- Conocer, en cualquier momento, el estado de los artículos enviados, es decir, si ya fueron asignados a un revisor, aceptados con o sin cambios, o rechazados.

- Participar en el proceso editorial corrigiendo y modificando sus artículos hasta su aceptación final. 